\title{
A Novel Method for Fabricating Double Layers Porous Anodic Alumina in Phosphoric/Oxalic Acid Solution and Oxalic Acid Solution
}

\author{
Yanfang Xu, ${ }^{1}$ Xiaojiu Li, ${ }^{1,2}$ Hao Liu, ${ }^{1,2,3}$ and Jie $\mathrm{Xu}^{1}$ \\ ${ }^{1}$ School of Textiles, Tianjin Polytechnic University, Tianjin 300387, China \\ ${ }^{2}$ Key Laboratory of Advanced Textile Composite Materials, Ministry of Education of China, Tianjin 300387, China \\ ${ }^{3}$ Research Institute of Smart Wearable Electronic Textiles, Tianjin Polytechnic University, Tianjin 300387, China
}

Correspondence should be addressed to Hao Liu; liuhao@tjpu.edu.cn

Received 20 December 2015; Accepted 28 February 2016

Academic Editor: Zhi Li Xiao

Copyright (C) 2016 Yanfang Xu et al. This is an open access article distributed under the Creative Commons Attribution License, which permits unrestricted use, distribution, and reproduction in any medium, provided the original work is properly cited.

\begin{abstract}
A novel method for fabricating ordered double layers porous anodic alumina (DL-PAA) with controllable nanopore size was presented. Highly ordered large pore layer with interpore distance of $480 \mathrm{~nm}$ was fabricated in phosphoric acid solution with oxalic acid addition at the potential of $195 \mathrm{~V}$ and the small pore layer was fabricated in oxalic acid solution at the potential from 60 to $100 \mathrm{~V}$. Experimental results show that the thickness of large pore layer is linearly correlative with anodizing time, and pore diameter is linearly correlative with pore widening time. When the anodizing potential in oxalic acid solution was adjusted from 60 to $100 \mathrm{~V}$, the small pore layers with continuously tunable interpore distance from 142 to $241 \mathrm{~nm}$ and pore density from $1.94 \times 10^{9}$ to $4.89 \times 10^{9} \mathrm{~cm}^{-2}$ were obtained. And the interpore distance and the pore density of small pore layers are closely correlative with the anodizing potential. The fabricated DL-PAA templates can be widely utilized for fabrication of ordered nanomaterials, such as superhydrophobic or gecko-inspired adhesive materials and metal or semiconductor nanowires.
\end{abstract}

\section{Introduction}

Porous anodic alumina (PAA) as a versatile nanoscale template has been widely used in numerous applications such as synthesis of nanowires [1], nanotubes [2], and nanodots [3], magnetic recording media [4], energy storage [5], catalysis [6], and biomaterials $[7,8]$. The porous structure of PAA is a key parameter to design and produce a broad range of nanostructures with exquisitely designed properties. The design and controlled synthesis of complex structure PAA including hierarchical, modulated, multilayer, funnel-like, and three-dimensional can promote the development of new nanostructure materials [9]. So far, several approaches, such as multistep anodization where the type of electrolyte or electrolyte concentration is changed after each step, varying the applied voltage or current during anodization or combining anodization and chemical etching, have made it possible to engineer the structure of PAA to produce a new generation of nanostructure with potential applications in functional materials [10]. To this end, Meng et al. [11] successfully fabricated multiply Y-branched pore structure by stepwise reduction of potential during the second step of anodization. They found that the number of branches $(n)$ had a relationship with the anodizing voltage by a factor of $1 / \sqrt{ } n$ during the anodizing process. Lee and Kim [12] reported a pulse anodization for the preparation of PAA with patternaddressed pore structure. Losic and Losic Jr. [13] demonstrated a cyclic anodization for fabricating three-dimensional PAA by combining cyclic anodization and chemical etching. For multilayer PAA, Ho et al. [14] reported the fabrication of multilayer three-dimensional PAA by sequentially stepping down the anodization potential while etching of the barrier layer is performed after each step. Santos et al. [15] fabricated hierarchical PAA templates by asymmetric two-step anodization with different geometric characteristics. However, the regularity of the multilayer PAA needs to be improved, and quantitative analysis of the pore size is also required. 


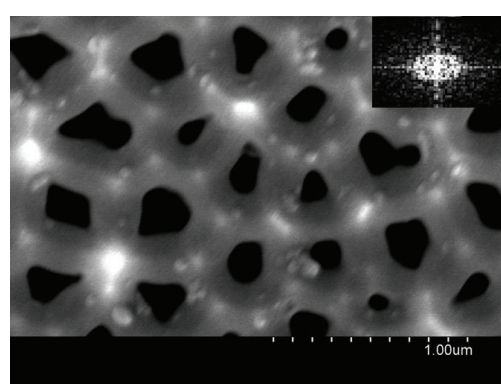

(a)

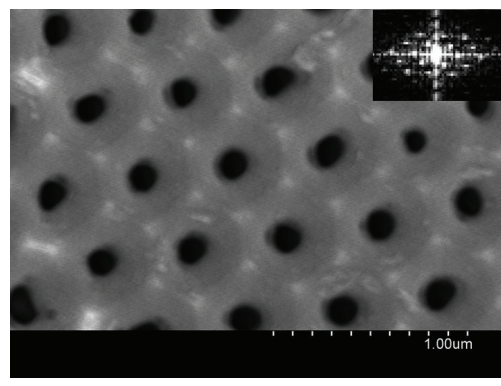

(c)

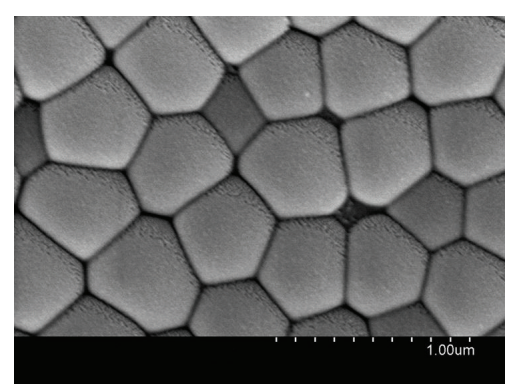

(b)

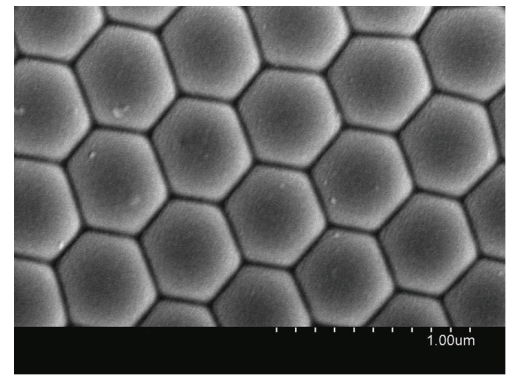

(d)

Figure 1: (a) Top and (b) bottom FE-SEM images of PAA fabricated in $1 \mathrm{wt} \% \mathrm{H}_{3} \mathrm{PO}_{4}$ electrolyte at $170 \mathrm{~V}$; (c) top and (d) bottom FE-SEM images of PAA fabricated in $1 \mathrm{wt} \% \mathrm{H}_{3} \mathrm{PO}_{4} / 0.03 \mathrm{M} \mathrm{H}_{2} \mathrm{C}_{2} \mathrm{O}_{4}$ at $195 \mathrm{~V}$.

In this paper, we present a novel method for fabricating ordered DL-PAA with a large pore layer and a small pore layer by three-step anodization. The large pore layer was fabricated by traditional two-step anodization in phosphoric acid with oxalic acid addition; the small pore layer was fabricated by third anodization in oxalic acid solution. The relationship of PAA thickness versus anodizing time and pore diameter versus pore widening time of large pore layer will be studied. The small pore layer with different interpore distance at corresponding anodizing potential will be discussed in detail. The limitation effect of the large pore layer on the formation of small pore layer also will be discussed. The obtained DL-PAA templates with different pore size have potential application in preparation of a broad range of ordered nanomaterials (such as superhydrophobic materials, gecko-inspired adhesive materials, and metal or semiconductor nanowires).

\section{Methods}

Highly pure aluminum sheets (99.999\%, Beijing Research Institute of Nonferrous Metal and Rare-Earth Application, China) with a thickness of $0.2 \mathrm{~mm}$ were used as the starting materials. The aluminum sheets were degreased in acetone and washed in deionized water and the natural oxide layer was removed in $10 \mathrm{wt} \% \mathrm{NaOH}$ for 10 minutes. The substrates were then electropolished in a 1:4 vol. mixture of perchloric acid and ethanol at the potential of $21 \mathrm{~V}$, temperature of 0 $3^{\circ} \mathrm{C}$, time of 5 minutes.

The first step anodization was conducted at the potential of $195 \mathrm{~V}$ in $1 \mathrm{wt} \%$ phosphoric acid electrolyte with $0.03 \mathrm{M}$ oxalic acid addition for 6 hours at $0-3^{\circ} \mathrm{C}$. The reaction area was $1 \mathrm{~cm}^{2}$. Subsequently, in order to obtain a highly ordered patterned $\mathrm{Al}$ surface, the sample was immersed into a mixture solution of $\mathrm{H}_{3} \mathrm{PO}_{4}(6 \%)$ and $\mathrm{CrO}_{3}(18 \mathrm{~g} / \mathrm{L})$ at $60^{\circ} \mathrm{C}$ for 6 hours to remove the alumina membrane. The conditions of the second anodization (large pore layer) were the same as the first step except that anodizing time was 15 minutes. Then the sample was immersed in $5 \mathrm{wt} \% \mathrm{H}_{3} \mathrm{PO}_{4}$ for 150 minutes for thinning the barrier layer and widening the pore at $30^{\circ} \mathrm{C}$. The small pore layer was formed in third step anodization performed in $0.15 \mathrm{M}$ oxalic acid at the potential from 60 to $100 \mathrm{~V}$ at $0-3^{\circ} \mathrm{C}$. During all anodizations, electrolytes were rigorously stirred.

The morphology of PAA membranes was measured using a HITACHI S-4800 Field-Emission Scanning Electron Microscope (FE-SEM). Image analyses of interpore distance, pore diameter, and oxide thickness were done with image analysis employing the IMAGEJ software.

\section{Results and Discussion}

Figures 1(a) and 1(b) show the top and bottom FE-SEM images of PAA fabricated in $1 \mathrm{wt} \% \mathrm{H}_{3} \mathrm{PO}_{4}$ at $170 \mathrm{~V}$ with inferior order; when the potential exceeds $170 \mathrm{~V}$, the PAA film would burn or break down due to a large amount of joule heat released from the anodization. By using phosphoric/oxalic acid mixed solution as anodizing electrolyte, our team has successfully fabricated highly ordered PAA with continuously tunable interpore distance from 300 to $500 \mathrm{~nm}$ in phosphoric/oxalic acid mixed electrolyte [16]. Here $0.03 \mathrm{M} \mathrm{H}_{2} \mathrm{C}_{2} \mathrm{O}_{4}$ addition in $1 \mathrm{wt} \% \mathrm{H}_{3} \mathrm{PO}_{4}$ was utilized for fabricating highly ordered PAA template with interpore distance of $480 \mathrm{~nm}$ at the potential of $195 \mathrm{~V}$. And Figures 1(c) and 1(d) show the top and bottom FE-SEM images of highly ordered PAA performed in the condition mentioned above. The Fast Fourier Transforms (FFT) images are also noticed. For the PAA 


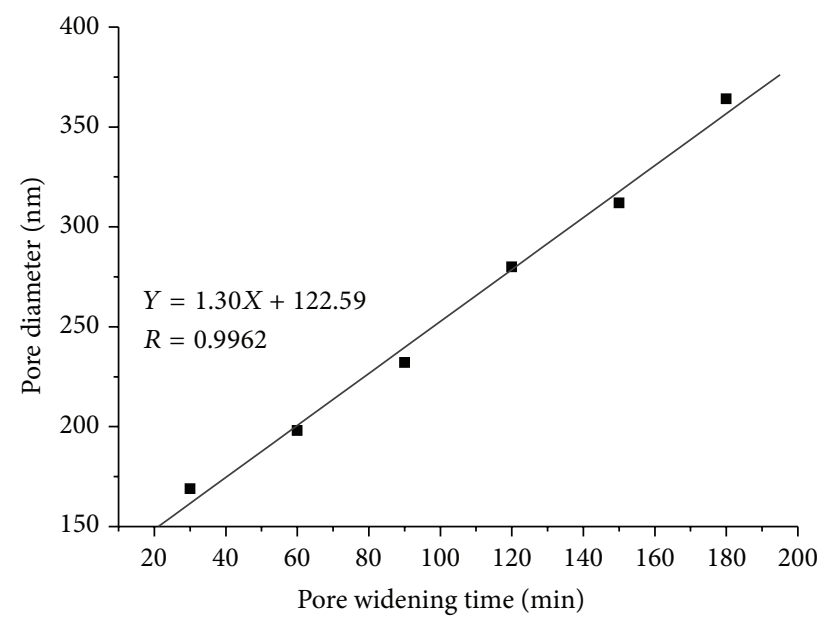

(a)

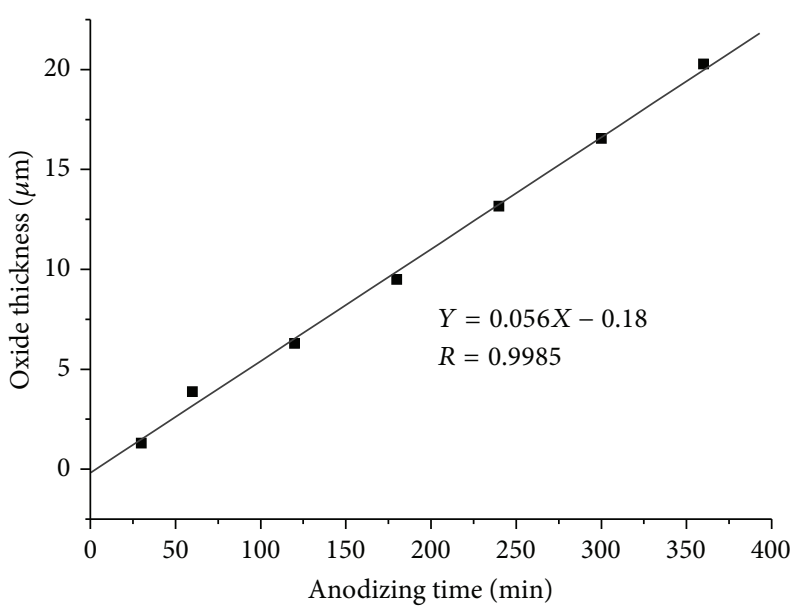

(b)

FIGURE 2: (a) Curve of pore diameter of large pore layer versus pore widening time. (b) Curve of thickness of large pore layer versus anodizing time.

fabricated in $1 \mathrm{wt} \% \mathrm{H}_{3} \mathrm{PO}_{4}$ at $170 \mathrm{~V}$, the dots in the FFT image are not so distinct suggesting a deterioration of the pore arrangement. For the PAA fabricated in $1 \mathrm{wt} \% \mathrm{H}_{3} \mathrm{PO}_{4} / 0.03 \mathrm{M}$ $\mathrm{H}_{2} \mathrm{C}_{2} \mathrm{O}_{4}$ at $195 \mathrm{~V}$, the FFT images have distinct dots at the edges of the hexagon, conforming good arrangement of the nanopores [17]. Next, we will use the above parameters ( $1 \mathrm{wt} \%$ $\mathrm{H}_{3} \mathrm{PO}_{4} / 0.03 \mathrm{M}$ oxalic acid mixed solution and $195 \mathrm{~V}$ anodizing potential) for fabricating the large pore layer of DL-PAA.

Figures 2(a) and 2(b) show the curves of pore diameter of large pore layer versus pore widening time and thickness of large pore layer versus anodizing time, respectively. Strong linear correlation is between pore diameter and pore widening time and between thickness and anodizing time; their correlation coefficients are all over 0.99 . Therefore, we can freely control the pore diameter and thickness of large pore layer of DL-PAA by adjusting pore widening time and anodizing time according to experimental design. However, to observe clearly the top large pore layer and the bottom small pore layer of DL-PAA simultaneously, the anodizing time of large pore layer was determined for 15 minutes.

After large pore layer of DL-PAA was fabricated, the small pore layer needs to be fabricated in oxalic acid solution. However, before fabricating small pore layer of DL-PAA, the barrier layer of large pore must be thinned (also a pore widening process), because high anodizing potential for fabricating large pore layer will make the barrier thicken and block subsequent anodization reaction in oxalic acid solution under low electric field condition. Figure 3 shows the top, bottom, and cross section FE-SEM images of the DL-PAA with the same large pore size and different small pore size. The large pore layers of DL-PAA in Figures 3(a), 3(b), 3(c), 3(d), and $3(\mathrm{e})$ were fabricated in $1 \mathrm{wt} \%$ phosphoric acid $/ 0.03 \mathrm{M}$ oxalic acid mixed electrolyte, at $0-3^{\circ} \mathrm{C}$ and $195 \mathrm{~V}$ for 15 minutes, and pores were widened in $5 \mathrm{wt} \%$ phosphoric acid for 150 minutes. The bottom layers of small pore layer of DL-PAA films are shown in Figures $3\left(\mathrm{a}^{\prime}\right), 3\left(\mathrm{~b}^{\prime}\right), 3\left(\mathrm{c}^{\prime}\right), 3\left(\mathrm{~d}^{\prime}\right)$, and $3\left(\mathrm{e}^{\prime}\right)$; small pore layers were fabricated in $0.15 \mathrm{M}$ oxalic acid at $0-3^{\circ} \mathrm{C}$ for 30 minutes at anodizing potential from 60 to $100 \mathrm{~V}$ with $10 \mathrm{~V}$ interval. The interpore distance of small pore layer is from 142 to $241 \mathrm{~nm}$. Previous studies indicated that interpore distance of PAA achieved under ordinary mild anodization (MA) and hard anodization (HA) depends linearly on anodizing potential with a proportional constant of $\zeta_{\mathrm{MA}}=2.5 \mathrm{~nm} \mathrm{~V}^{-1}$ and $\zeta_{\mathrm{HA}}=2.0 \mathrm{~nm} \mathrm{~V}^{-1}$, respectively [18, 19]. The proportional constant of small pore layer is $2.22 \mathrm{~nm}$ $\mathrm{V}^{-1}$ (Figure 4), which is between MA and HA. This is largely attributed to the limitation of the large pore layer; the large barrier layer curvature of the large pore imposes restriction on the small pore rearrangement. Figures $3\left(\mathrm{a}^{\prime \prime}\right), 3\left(\mathrm{~b}^{\prime \prime}\right), 3\left(\mathrm{c}^{\prime \prime}\right)$, $3\left(\mathrm{~d}^{\prime \prime}\right)$, and $3\left(\mathrm{e}^{\prime \prime}\right)$ show the cross section of DL-PAA. One can see that small pore layer continued growing on the basis of the large pore layer, and double layer structure was formed. Notably, some small pore was not vertically downward but was in a direction perpendicular to the curvature of the barrier layer. The limitation effect of the first layer with large curvature of the barrier layer weakens with the anodizing potential increases in the process of fabricating small pore layer. Figure 4 also shows the relationship between thickness of the small pore layer and anodizing potential. For a given duration of anodizing time (30 minutes), the thickness of the small pore layer increases with increasing current density and consequently with increasing potential. Therefore, with the increasing potential, an exponential increase of oxide thickness of the small pore layer is observed.

For ideally ordered porous PAA, pore density $n$ was defined as the total number of pores occupying the surfaces area of $1 \mathrm{~cm}^{2}$ as expressed by the following equation [20]:

$$
n=\left(\frac{2}{\sqrt{3} D^{2}{ }_{\text {int }}}\right) \times 10^{14} \mathrm{~cm}^{-2}
$$

where $n$ denotes pore density and $D_{\text {int }}$ denotes interpore distance. Duo to the fact that interpore distance has linear relationship with anodizing potential, as can be expected, 


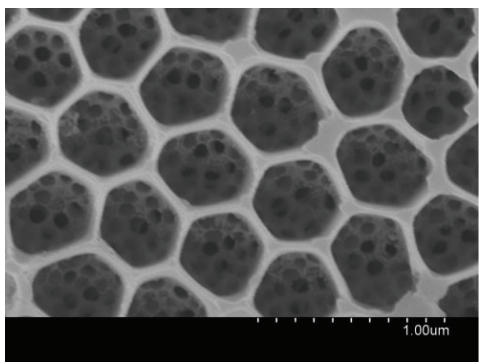

(a)

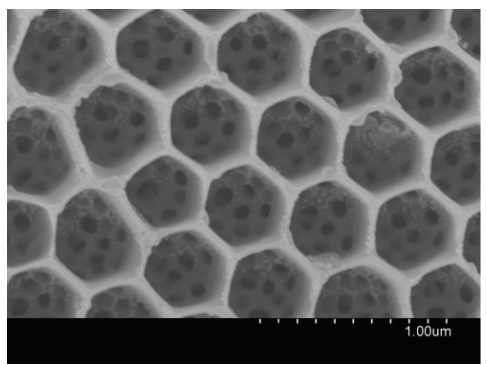

(b)

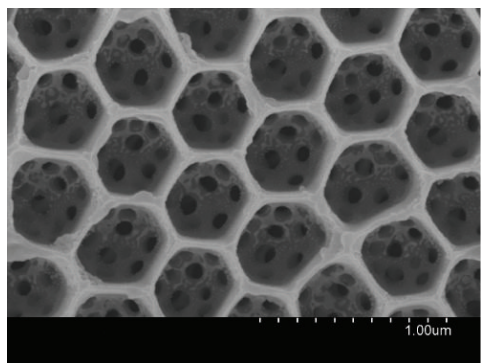

(c)

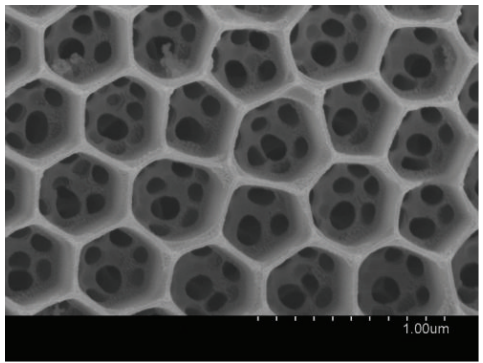

(d)

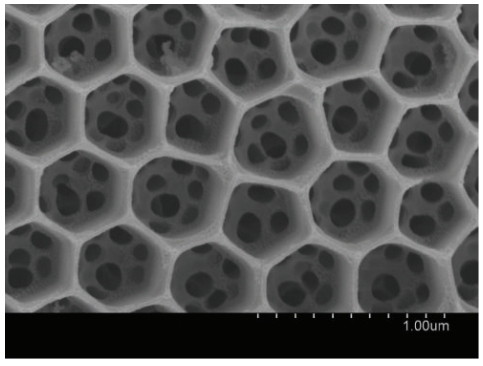

(e)

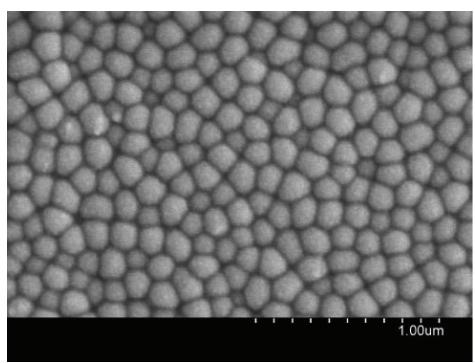

$\left(a^{\prime}\right)$

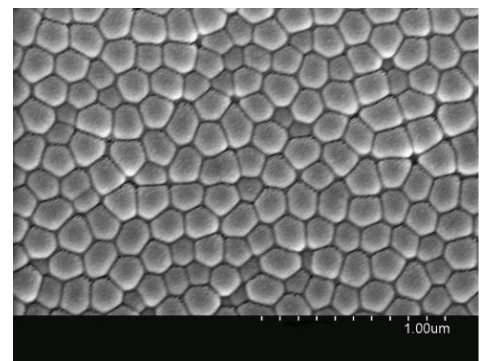

$\left(\mathrm{b}^{\prime}\right)$

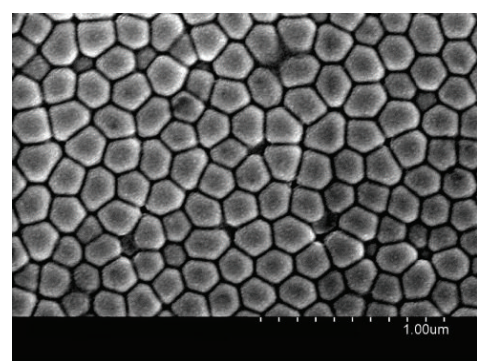

(c')

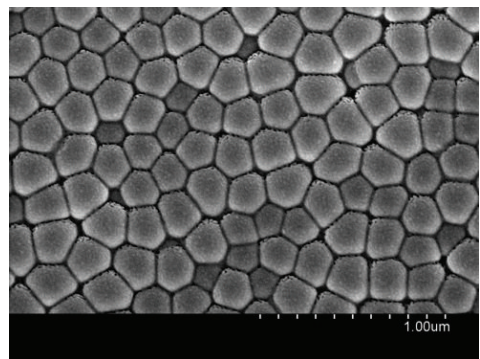

$\left(d^{\prime}\right)$

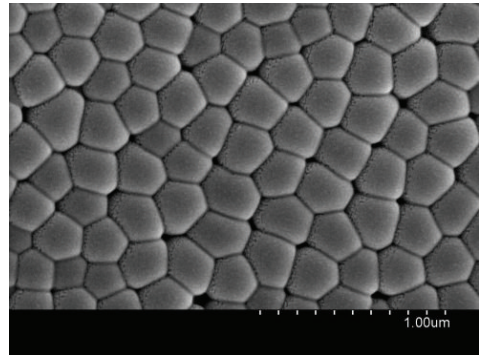

$\left(\mathrm{e}^{\prime}\right)$

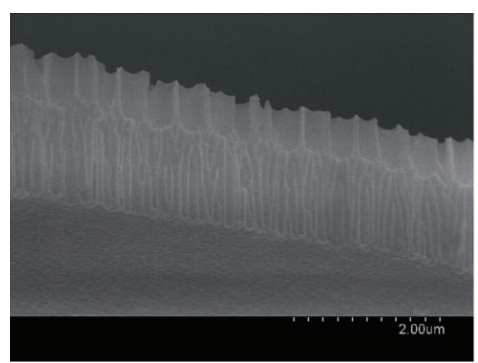

$\left(a^{\prime \prime}\right)$

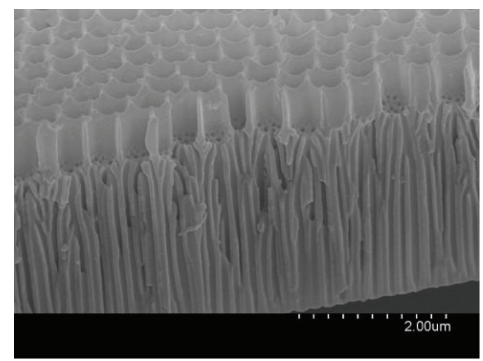

$\left(b^{\prime \prime}\right)$

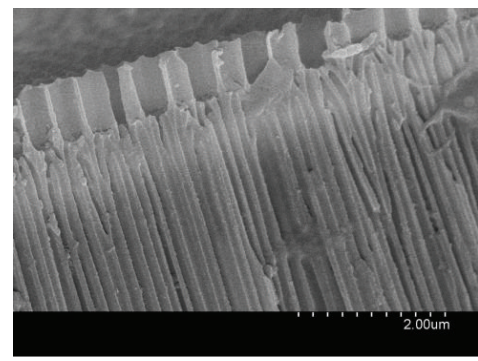

$\left(c^{\prime \prime}\right)$

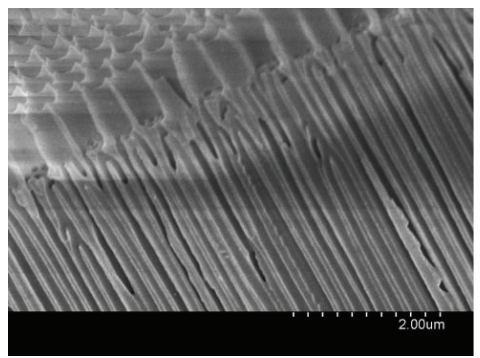

$\left(d^{\prime \prime}\right)$

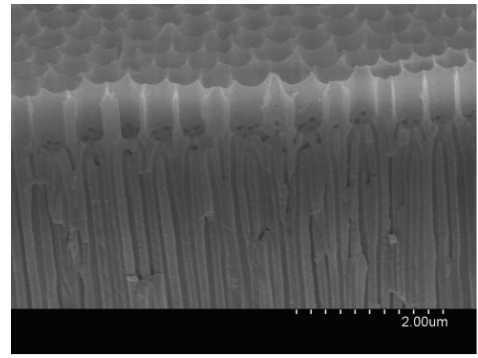

$\left(e^{\prime \prime}\right)$

FIgURE 3: Top, bottom, and cross section FE-SEM images of DL-PAA with small pore layer fabricated at the potential of (a, $\left.\mathrm{a}^{\prime}, \mathrm{a}^{\prime \prime}\right) 60 \mathrm{~V},(\mathrm{~b}$, $\left.\mathrm{b}^{\prime}, \mathrm{b}^{\prime \prime}\right) 70 \mathrm{~V},\left(\mathrm{c}, \mathrm{c}^{\prime}, \mathrm{c}^{\prime \prime}\right) 80 \mathrm{~V},\left(\mathrm{~d}, \mathrm{~d}^{\prime}, \mathrm{d}^{\prime \prime}\right) 90 \mathrm{~V}$, and $\left(\mathrm{e}, \mathrm{e}^{\prime}, \mathrm{e}^{\prime \prime}\right) 100 \mathrm{~V}$. 
TABLE 1: Structure parameters of small pore layer formed by three-step anodization.

\begin{tabular}{lcccc}
\hline Potential $(\mathrm{V})$ & Interpore distance $(\mathrm{nm})$ & Oxide thickness $(\mu \mathrm{m})$ & Pore density measured $\left(10^{9} / \mathrm{cm}^{-2}\right)$ & Pore density theoretical $\left(10^{9} / \mathrm{cm}^{-2}\right)$ \\
\hline 60 & 142 & 1.24 & 4.89 & 5.64 \\
70 & 158 & 2.63 & 3.86 & 4.45 \\
80 & 181 & 5.46 & 3.03 & 3.52 \\
90 & 204 & 14.08 & 2.42 & 2.79 \\
100 & 241 & 26.23 & 1.94 & 2.16 \\
\hline
\end{tabular}

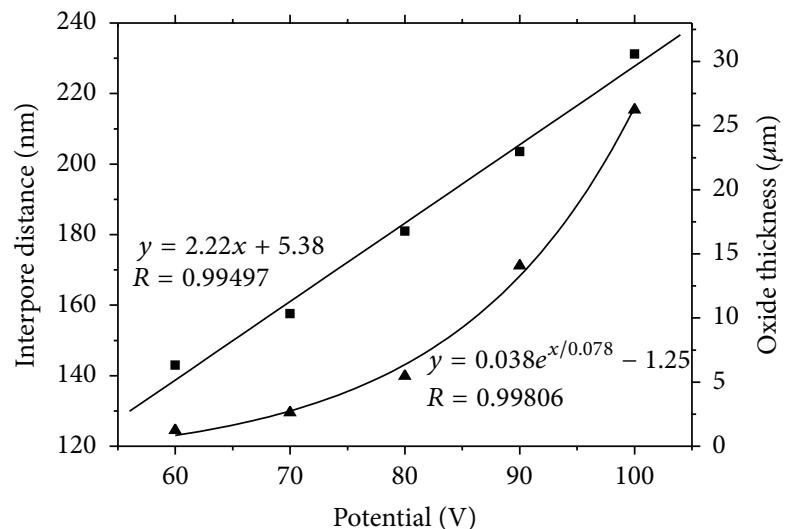

- Interpore distance

- Oxide thickness

FIGURE 4: Curves of interpore distance and oxide thickness versus third anodizing potential of the small pore layer.

pore density (both measured value and theoretical value) decreases exponentially with increasing potential (Figure 5). Table 1 shows the analysis results of the small pore layer at corresponding potential. We can see that theoretical value of pore density of small pore layer is bigger than that of measured, which is also largely attributed to the limitation of the first layer with large curvature of the barrier layer.

\section{Conclusions}

In summary, we have presented a novel method for fabricating ordered DL-PAA with controllable pore size in phosphoric/oxalic acid solution and oxalic acid solution. The addition of oxalic acid in phosphoric acid solution can improve the anodizing potential and obviously improve the regularity of PAA. Highly ordered large pore PAA with interpore distance of $480 \mathrm{~nm}$ was successfully fabricated. It was found that pore diameter of large pore layer has a linear relationship with pore widening time, and the oxide thickness has a linear relationship with anodizing time. After the barrier layer thinning process of large pore layer, DL-PAA films were obtained by performing in oxalic acid solution at the potential from 60 to $100 \mathrm{~V}$ with interpore distance of small pore layer from 142 to $241 \mathrm{~nm}$ and pore density from $1.94 \times 10^{9}$ to $4.89 \times$ $10^{9} \mathrm{~cm}^{-2}$. The interpore distance of small pore layer is linearly correlated with anodizing potential, and oxide thickness has exponential function relationship with anodizing potential.

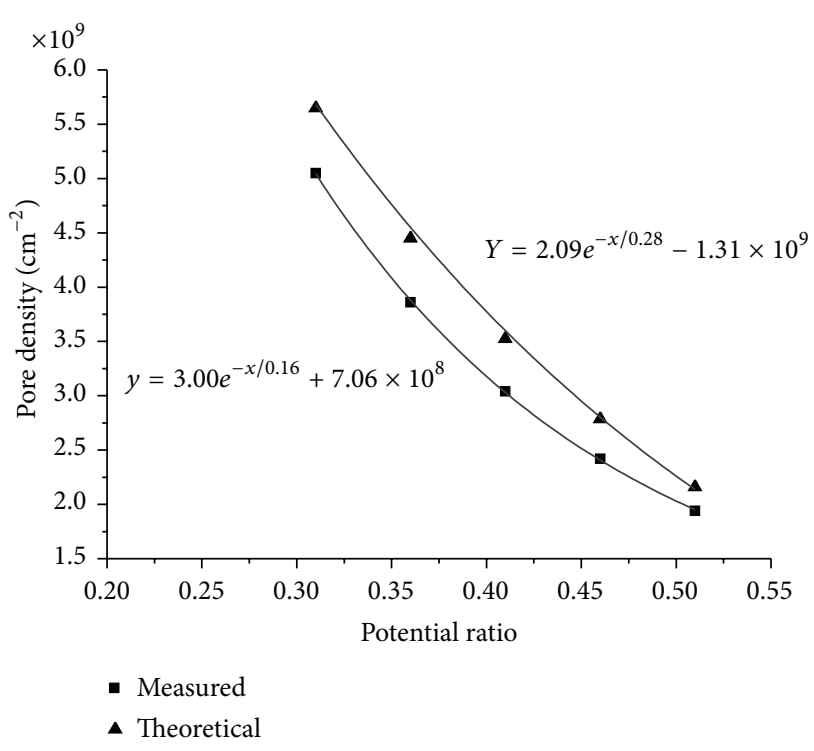

FIGURE 5: Curves of pore density versus potential of small pore layer.

\section{Competing Interests}

There are no competing interests regarding the publication of this paper.

\section{Acknowledgments}

The authors would like to thank the National Natural Science Foundation of China (Grant no. 51473122), High Level Talent Project of Xiamen University of Technology: Research of Health Monitoring Smart Garments Based on Flexible Sensors System (no. YKJ13039), and Tianjin City High School Science \& Technology Fund Planning Project (Grant no. 20120321) for support of the work reported in this paper.

\section{References}

[1] L. Zaraska, G. D. Sulka, and M. Jaskuła, "Fabrication of free-standing copper foils covered with highly-ordered copper nanowire arrays," Applied Surface Science, vol. 258, no. 19, pp. 7781-7786, 2012.

[2] Y. Yu, K. Kant, J. G. Shapter, J. Addai-Mensah, and D. Losic, "Gold nanotube membranes have catalytic properties," Microporous and Mesoporous Materials, vol. 153, pp. 131-136, 2012.

[3] R. Valeev, E. Romanov, A. Beltukov, V. Mukhgalin, I. Roslyakov, and A. Eliseev, "Structure and luminescence characteristics of $\mathrm{ZnS}$ nanodot array in porous anodic aluminum oxide," Physica 
Status Solidi (C) Current Topics in Solid State Physics, vol. 9, no. 6, pp. 1462-1465, 2012.

[4] K. Nielsch, R. B. Wehrspohn, J. Barthel et al., "Hexagonally ordered $100 \mathrm{~nm}$ period nickel nanowire arrays," Applied Physics Letters, vol. 79, no. 9, pp. 1360-1362, 2001.

[5] M. Norek, W. J. Stępniowski, D. Zasada, K. Karczewski, J. Bystrzycki, and Z. Bojar, " $\mathrm{H}_{2}$ absorption at ambient conditions by anodized aluminum oxide (AAO) pattern-transferred Pd nanotubes occluded by Mg nanoparticles," Materials Chemistry and Physics, vol. 133, no. 1, pp. 376-382, 2012.

[6] S.-Z. Chu, S. Inoue, K. Wada, S. Hishita, and K. Kumshima, "Self-organized nanoporous anodic titania films and ordered titania nanodots/nanorods on glass," Advanced Functional Materials, vol. 15, no. 8, pp. 1343-1349, 2005.

[7] C. R. Martin, "Nanomaterials: a membrane-based synthetic approach,” Science, vol. 266, no. 5193, pp. 1961-1966, 1994.

[8] A. Thormann, N. Teuscher, M. Pfannmöller, U. Rothe, and A. Heilmann, "Nanoporous aluminum oxide membranes for filtration and biofunctionalization," Small, vol. 3, no. 6, pp. 10321040, 2007.

[9] A. Santos, T. Kumeria, and D. Losic, "Nanoporous anodic alumina: a versatile platform for optical biosensors," Materials, vol. 7, no. 6, pp. 4297-4320, 2014.

[10] A. M. Md Jani, D. Losic, and N. H. Voelcker, "Nanoporous anodic aluminium oxide: advances in surface engineering and emerging applications," Progress in Materials Science, vol. 58, no. 5, pp. 636-704, 2013.

[11] G. W. Meng, Y. J. Jung, A. Y. Cao, R. Vajtai, and P. M. Ajayan, "Controlled fabrication of hierarchically branched nanopores, nanotubes, and nanowires," Proceedings of the National Academy of Sciences of the United States of America, vol. 102, no. 20, pp. 7074-7078, 2005.

[12] W. Lee and J.-C. Kim, "Highly ordered porous alumina with tailor-made pore structures fabricated by pulse anodization," Nanotechnology, vol. 21, no. 48, Article ID 485304, 2010.

[13] D. Losic and D. Losic Jr., "Preparation of porous anodic alumina with periodically perforated pores," Langmuir, vol. 25, no. 10, pp. 5426-5431, 2009.

[14] A. Y. Y. Ho, H. Gao, Y. C. Lam, and I. Rodríguez, “Controlled fabrication of multitiered three-dimensional nanostructures in porous alumina," Advanced Functional Materials, vol. 18, no. 14, pp. 2057-2063, 2008.

[15] A. Santos, J. Ferré-Borrull, J. Pallarès, and L. F. Marsal, "Hierarchical nanoporous anodic alumina templates by asymmetric two-step anodization," Physica Status Solidi A, vol. 208, no. 3, pp. 668-674, 2011.

[16] Y. F. Xu, H. Liu, X. J. Li, W. M. Kang, B. W. Cheng, and X. J. $\mathrm{Li}$, "A novel method for fabricating self-ordered porous anodic alumina with wide interpore distance using phosphoric/oxalic acid mixed electrolyte," Materials Letters, vol. 151, pp. 79-81, 2015.

[17] W. J. Stępniowski and Z. Bojar, "Synthesis of anodic aluminum oxide (AAO) at relatively high temperatures. Study of the influence of anodization conditions on the alumina structural features," Surface \& Coatings Technology, vol. 206, no. 2-3, pp. 265-272, 2011.

[18] A. P. Li, F. Müller, A. Bimer, K. Nielsch, and U. Gösele, "Hexagonal pore arrays with a 50-420 $\mathrm{nm}$ interpore distance formed by self-organization in anodic alumina," Journal of Applied Physics, vol. 84, no. 11, pp. 6023-6026, 1998.
[19] W. Lee, R. Ji, U. Gösele, and K. Nielsch, "Fast fabrication of long-range ordered porous alumina membranes by hard anodization," Nature Materials, vol. 5, pp. 741-747, 2006.

[20] W. Lee and S.-J. Park, "Porous anodic aluminum oxide: anodization and templated synthesis of functional nanostructures," Chemical Reviews, vol. 114, no. 15, pp. 7487-7556, 2014. 

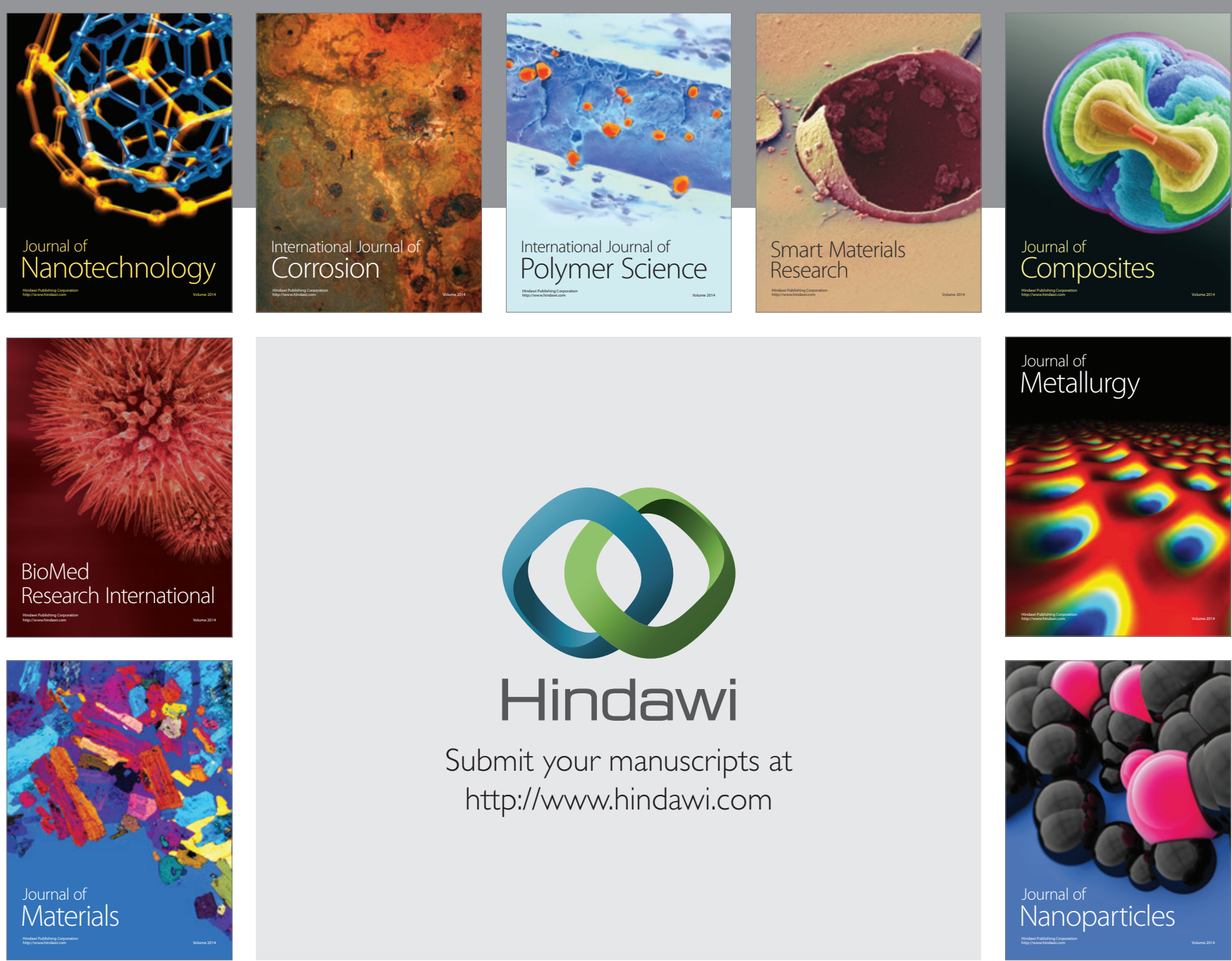

\section{Hindawi}

Submit your manuscripts at

http://www.hindawi.com

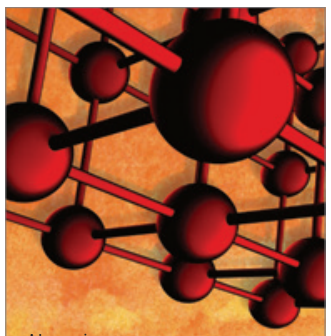

Materials Science and Engineering
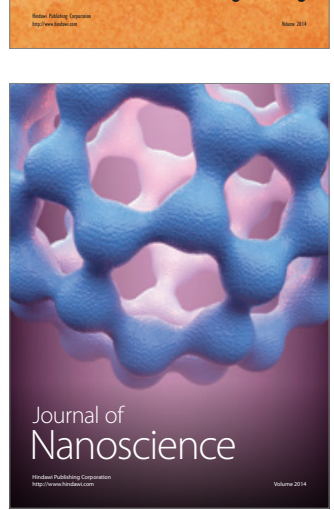
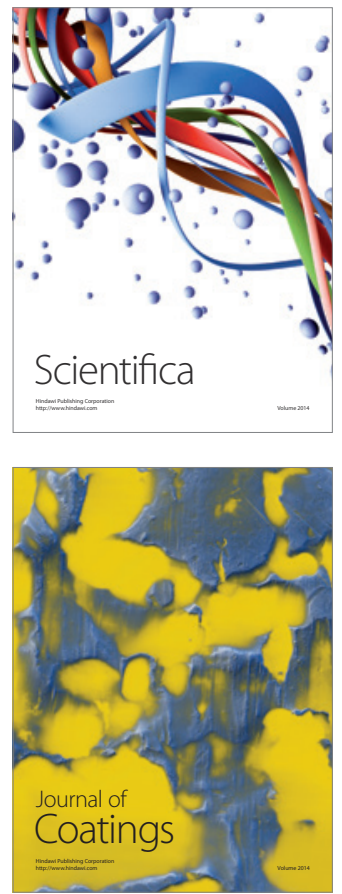
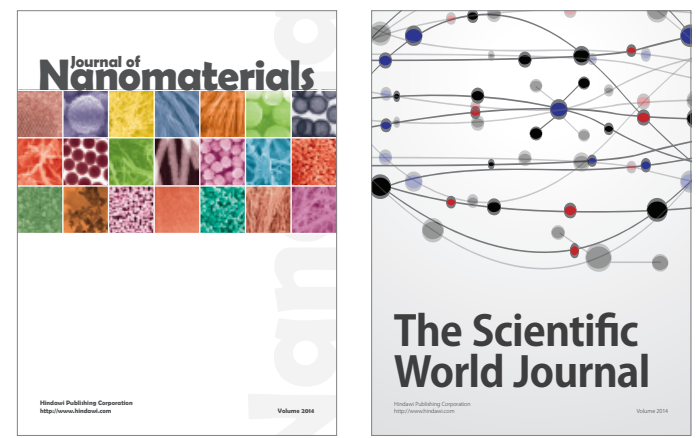

The Scientific World Journal
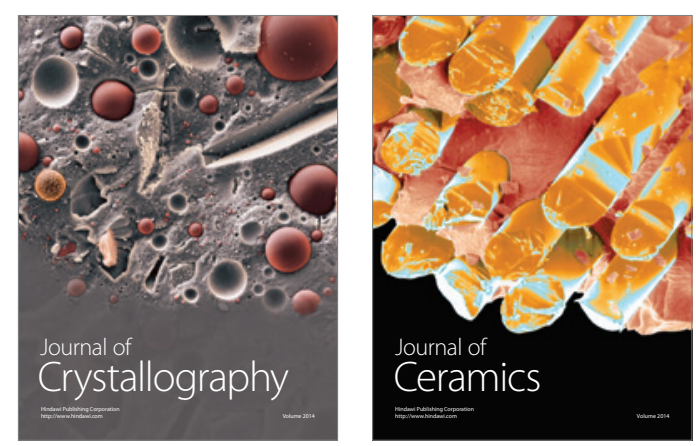
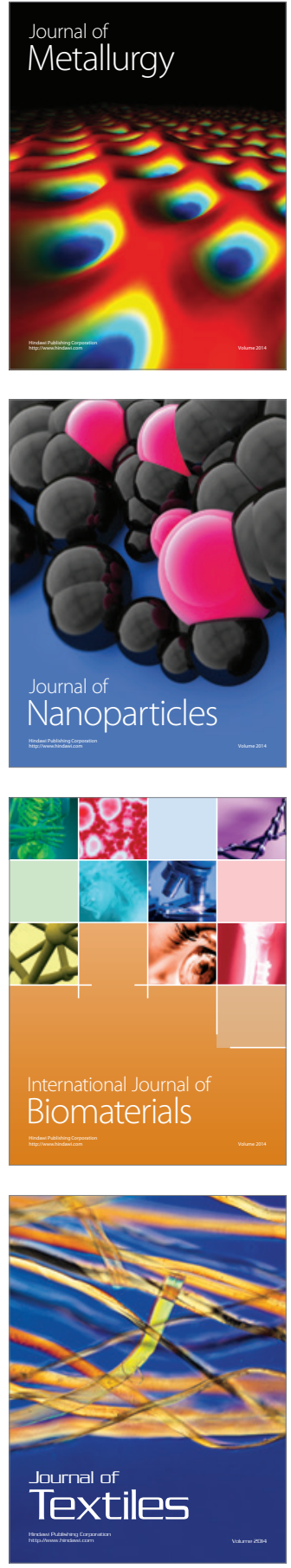